\title{
Correlation Analysis between Industrial Structure Change and Regional Economic Growth -- Taking Hubei Province as an Example
}

\author{
Tengyuan Zhang ${ }^{a}$, Chuanjie Zhang ${ }^{\text {b }}$ \\ School of Business Administration, Zhongnan University of Economics and Law, China. \\ a1156817778@qq.com, bchuanjz2000@163.com
}

Keywords: Industrial structure change, economic growth, grey relational analysis, Hubei Province.

\begin{abstract}
The industrial structure has a profound impact on the development of regional economy, and the rational layout of industrial structure can promote the rapid growth of regional economy. Based on the research status of industrial structure change, this paper takes Hubei Province as an example, based on the theory of grey correlation analysis, and uses the statistical yearbook of Hubei Province in 2016 to explore the relationship between the industrial structure change and regional economic growth in Hubei province by the statistical data of relevant websites. The study found that the industrial structure of Hubei province has changed obviously in the last ten years. The impact of the first industry on economic growth has gradually decreased, the impact of the third industry on economic growth has gradually increased, and the proportion of the third industry and the second industry is gradually equal, and the trend of catching up with the second industry is to be overtaken.
\end{abstract}

\section{Preface}

Industry is an important driving force for regional economic prosperity and development. Theoretically speaking, regional economic development is closely related to regional industrial structure. To explore the relationship between the changes of industrial structure and regional growth is helpful to the scientific planning and distribution of regional industrial structure, and to promote the stability, rapid and sustainable development of regional economy. At the present stage, China is in the period of social and economic transformation and development, and the change of regional industrial structure is becoming more and more significant. In order to ensure the smooth and rapid growth of regional economy, it is necessary to further clarify the relationship between the changes of industrial structure and regional economic growth. This paper, taking Hubei Province as an example, explores the relationship between the change of industrial structure and regional economic growth, which aims to clarify the relationship between regional industrial structure change and regional economic growth, firmly grasp the important influence factors of regional economic growth, and provide some ideas for the establishment, adjustment and optimization of regional industrial policies. And suggestions.

\section{Industry Status in Hubei Province}

The core power of regional economic growth is the change of industrial structure. The relationship between economic growth and industrial structure has a certain interdependence and mutual influence. The change of industrial structure is the basis for realizing economic growth, and the economic growth also counteracts on the industrial structure and provides the necessary economic and environmental support for the reform of the industrial structure. As a major economic entity in Central China, Hubei province plays an important role in socialist economic construction. In recent years, a series of notable achievements have been made in the economic construction of Hubei Province, but at the same time, Hubei province still has the problem of irrational industrial structure. Over the past ten years, Hubei's economic construction has made leaps and bounds. In 2000, the total GDP of Hubei province was 354 billion 500 million yuan. In 2013, Hubei's GDP reached 24668 billion yuan, with an average increase of $16.2 \%$. In 2016, the total amount of GDP in Hubei reached 
32297 billion yuan, up $8.1 \%$ from last year; the national GDP growth rate was $6.7 \%$ in the same year, and the growth rate of GDP in Hubei was 1.4 percentage points higher than that of the national GDP.

The proportion of the three major industries in Hubei is in a dynamic developing process. In 2012, the proportion of the primary industry, the second industry and the third industry in Hubei was 13:50:37. In 2014, the proportion of the three major industries in Hubei was 11:47:42. In 2015, the proportion of the three industries was 11:46:43. It can be seen that in the three major industrial systems, the proportion of the primary industry and the second industry is decreasing year by year, and the proportion of the third industries is gradually improving. Among the three major industrial systems, the growth rate of the second industry is relatively high, the growth rate in the past ten years has been maintained at over $10 \%$, and the third industry has followed closely. The growth of the first industry is slower. In general, the important position of the second industry and the third industry in the economic system of Hubei has become increasingly prominent, and the influence of the first industry on the economic development of Hubei has gradually weakened.

\section{Research Methods}

Based on the grey relational theory, this paper analyzes the correlation between the change of industrial structure and regional economic growth in Hubei province. Professor Deng Julong first proposed the grey relational theory in 1982. The so-called degree of association refers to the correlation between two systems, which vary with time or object. In the course of the development of the two systems, if the trend of the two factors is consistent (synchronous change), then the correlation degree of the two can be higher, and vice versa. Grey relational analysis is an analytical method to evaluate the correlation between factors based on the synchronous degree of the development trend of factors. According to Professor Deng Julong's method, only two sequences (reference sequence and comparison sequence) are needed, which can be used as the basis to reflect the economic characteristics. The specific methods of operation are as follows:

Determine the reference column $X 0$ and the comparison sequence $X j . X 0=\{X 0(k) \mid k=1,2 \ldots n\}$. $\mathrm{Xu}=\{\mathrm{Xu}(\mathrm{k}) \mid \mathrm{k}=1,2 \ldots \mathrm{n}\}$. The $\mathrm{k}$ in the formula is the number of times.

The correlation system of the comparison sequence $\mathrm{Xj}$ at the $\mathrm{k}$ time and the reference sequence $\mathrm{X} 0$ is calculated and compared. The formula is as follows:

$$
h_{\mathrm{j}}=\frac{\min _{j} \min _{k}\left|\mathrm{x}_{0}(\mathrm{k})-\mathrm{x}_{\mathrm{j}}(\mathrm{k})\right|+\rho \max _{j} \max _{\mathrm{k}}\left|\mathrm{x}_{0}(\mathrm{k})-\mathrm{x}_{\mathrm{j}}(\mathrm{k})\right|}{\left|\mathrm{x}_{0}(\mathrm{k})-\mathrm{x}_{j}(k)\right|+\rho \max _{j} \max _{k}\left|x_{0}(k)-x_{j}(k)\right|}
$$

The $\rho$ in the formula is the resolution coefficient, and the range is $[0,1]$. In general, the larger the difference coefficient, the greater the resolution. Here we choose $\rho=0.5$.In this formula, $\rho \max _{j} \operatorname{maxk} \mid \mathrm{x}_{0}(\mathrm{k})-\mathrm{x}_{\mathrm{j}}(\mathrm{k})$ is Maximum difference of two stage, similarly, $\rho \max _{j} \max \mid x_{0}(k)-x_{j}(k)$ is Minimum difference of two level.

Calculate the degree of association. The correlation coefficient is an index that depicts the correlation degree between the number of series and the reference series at the same time. A correlation coefficient is obtained by the formula each time. The correlation coefficient can be obtained by integrating the correlation coefficient with the mathematical relation. The correlation degree $\mathrm{R}$ can be obtained. The calculation formula is as follows:

$\mathrm{r}_{j}=\frac{1}{n} \sum_{k=1}^{n} h_{j}(k)$.It can be seen from the formula that the correlation degree can be obtained by processing the average correlation coefficient of each time.

\section{Analysis of the Correlation between Industrial Structure Change and Regional Economic Growth}

Based on the above theory and method, explore the correlation analysis of industrial structure change to regional economic growth.the GDP value of Hubei province of 2007 to 2016 years (10 years) is selected as the reference series, and the output value of the first industry, the second industry 
and the third industry in the corresponding years is selected as the comparison series. The correlation coefficient between the three industries and GDP in each year is calculated as follows.

Table 1. Correlation coefficient between three industries and GDP in Hubei Province in 2007-2016

\begin{tabular}{cccccc}
\hline \multicolumn{7}{c}{ years } \\
\hline Particular year & 2007 & 2008 & 2009 & 2010 & 2011 \\
\hline Primary industry & 0.7214 & 0.7125 & 0.7024 & 0.6985 & 0.6541 \\
The secondary industry & 0.8854 & 0.8921 & 0.8421 & 0.8921 & 0.8124 \\
the tertiary industry & 0.6621 & 0.6984 & 0.7124 & 0.7864 & 0.7941 \\
Particular year & 2012 & 2013 & 2014 & 2015 & 2016 \\
Primary industry & 0.6221 & 0.6004 & 0.6112 & 0.5984 & 0.6002 \\
The secondary industry & 0.7924 & 0.7886 & 0.7684 & 0.7851 & 0.7114 \\
the tertiary industry & 0.8241 & 0.8364 & 0.8641 & 0.8924 & 0.9224 \\
\hline
\end{tabular}

The relationship between the first industry and GDP is calculated $r 1=0.6623$; the correlation degree between the second industry and GDP is r2 $=0.8554$; the correlation degree between the third industry and GDP is r3=0.8721. According to the results obtained, in the past ten years, the second industry and the third industry have the greatest impact on economic growth, and the first industry has the least impact on economic growth. The impact of the second industry on economic growth in ten years is dominant. The impact of the third industry on economic growth has gradually increased. This also shows that the third industry is the main direction of the transformation of Hubei's industrial structure. The impact of the primary industry on economic growth has gradually weakened.

\section{Summary}

In summary, the change of industrial structure is closely related to regional economic growth. In the industrial structure of Hubei Province, the proportion of the primary industry has gradually decreased, the proportion of the third industry has been increasing, and the second industry accounts for a slight fluctuation. In the past 2007-2016 years, the second industry has always had a dominant impact on Hubei's economic growth. In the meantime, the impact of the first industry on economic growth has gradually weakened, and the role of the third industry for economic growth has gradually increased, which is also in line with the trend of social and economic transformation and development in China at present.

\section{References}

[1]. Rong-Chao GuoResearch. On the adjustment and upgrading of traditional industrial structure in the period of [1]. Transformation: taking Hubei Province as an example [J]. Journal of South-Central University for Nationalities: Humanities and Social Sciences Edition, 2004, 24 (1): 25-29.

[2]. Tian Tao. Research on the relationship between industrial structure adjustment and implementation of sustainable development strategy -- Taking Hubei Province as an example, [J]. Shopping malls modernization, 2007 (2): 237-237.

[3]. Tang Kemin. Speed up the adjustment of industrial structure and promote the sustainable development of economy. Take Hubei Province as an example, [J]. Economist, 2005 (7): 255-256.

[4]. Yao Li. The strategic choice to speed up the adjustment of industrial structure -- Taking Hubei's industrial structure as an example, [J]. Learning monthly, 2013 (17). 